\title{
Correlation between biaxial stress and free exciton transition in AIN epilayers
}

\author{
B. N. Pantha, N. Nepal, T. M. Al Tahtamouni, M. L. Nakarmi, J. Li, \\ J. Y. Lin, and H. X. Jiang ${ }^{\text {a) }}$ \\ Department of Physics, Kansas State University, Manhattan, Kansas 66506-2601, USA
}

(Received 6 June 2007; accepted 31 August 2007; published online 20 September 2007)

\begin{abstract}
Photoluminescence (PL) spectroscopy and x-ray diffraction measurements were employed to study biaxial strain in AlN epilayers grown on different substrates. X-ray diffraction revealed that AlN epilayers grown on AlN bulk substrates (or homoepilayers) have the same lattice parameters as AIN bulk crystals and are almost strain-free. Compared to the free exciton (FX) transition in an AlN homoepilayer, the FX line was $31 \mathrm{meV}$ higher in AlN/sapphire due to a compressive strain and 55 (69) $\mathrm{meV}$ lower in $\mathrm{AlN} / \mathrm{SiC}$ (AlN/Si) due to a tensile strain. A linear relationship between the FX transition energy peak position and in-plane stress was obtained, and a value of $45 \mathrm{meV} / \mathrm{GPa}$ for the linear coefficient of the stress-induced bandgap shift in AlN epilayers was deduced. The work here establishes PL as another simple and effective method for monitoring the biaxial stress in AlN epilayers. (C) 2007 American Institute of Physics. [DOI: 10.1063/1.2789182]
\end{abstract}

AlN has emerged as an active photonic material for applications in deep ultraviolet (DUV) emitters and detectors because of its large direct bandgap of $6.1 \mathrm{eV} .{ }^{1,2}$ It has strong chemical bonds, making it highly stable and resistant to degradation when operating under harsh environments/ conditions. Due to its high thermal conductivity, large piezoelectric field, and low electron affinity, AlN also has applications in stable $\mathrm{x}$-ray production, surface acoustic wave (SAW) devices, and electron emission devices. ${ }^{3-5}$ Like $\mathrm{GaN}$, thin AlN films grown on foreign substrates generally are plagued by a high threading dislocation density on the order of $\sim 10^{9}-10^{10} \mathrm{~cm}^{-2}$. ${ }^{6-8}$ Furthermore, if not properly managed, the stress induced by the thermal expansion coefficient mismatch between AIN and substrate may cause cracks in relatively thick epilayers. Much progress has been recently made for obtaining AlN bulk single crystal substrates. ${ }^{9-11}$ The use of an AlN bulk single crystal as a substrate is expected to significantly enhance the overall AlN epilayer quality due to its better lattice constant and thermal expansion coefficient matches to the subsequent epilayers over other substrates. There have been significant advances in the epitaxial growth of high quality AIN epilayers ${ }^{12-21}$ and AlN based active photonic device structures ${ }^{1,2}$ on sapphire, $\mathrm{SiC}, \mathrm{Si}$, and AlN bulk substrates.

A systematic comparative study concerning the basic structural and optical properties of AIN epilayers grown on various substrates is needed because of the increased importance of AlN for various applications and the diverse choices of substrates. However, this has been highly challenging because the growth conditions of AIN epilayers on different substrates have to be independently optimized. In this letter, we report on the epitaxial growth, DUV photoluminescence (PL) and X-ray diffraction (XRD) studies of AlN epilayers grown on sapphire, $\mathrm{SiC}, \mathrm{Si}$, and AlN bulk single crystal substrates. The variations of the free exciton emission peak positions and lattice constants with respect to the growth substrate have been probed and correlated. It was confirmed that AlN epilayers grown on AlN bulk substrates (or ho-

\footnotetext{
${ }^{a)}$ Electronic mail: jiang@phys.ksu.edu
}

moepilayers) have the same lattice parameters as AlN bulk crystals and are almost strain-free, while AlN heteroepilayers grown on sapphire substrates experience a compressive strain, and those grown on $\mathrm{SiC}$ and $\mathrm{Si}$ substrates undergo a tensile strain. Based on the variations of the free exciton (FX) emission peak position and lattice constant with respect to the growth substrate, a linear relationship between the FX transition and in-plane stress was obtained and a value of $45 \mathrm{meV} / \mathrm{GPa}$ for the linear coefficient of the stress-induced bandgap shift in AlN epilayers was deduced.

The $1 \mu \mathrm{m}$ thick undoped AlN epilayers were grown on bulk AlN, sapphire (0001), Si (111), and 4H-SiC (0001) substrates by metal organic chemical vapor deposition (MOCVD). The AlN epilayers were grown at $1050{ }^{\circ} \mathrm{C}$ on $\mathrm{Si}$ and $1300{ }^{\circ} \mathrm{C}$ on sapphire, $\mathrm{SiC}$, and AlN substrates. The DUV PL spectroscopy system employed consists of a frequency quadrupled 100 fs Ti:sapphire laser with an average power of $3 \mathrm{~mW}$ with excitation photon energy set at $197 \mathrm{~nm}$ or $6.28 \mathrm{eV}$ (repetition rate of $76 \mathrm{MHz}$ ), and a $1.3 \mathrm{~m}$ monochromator. $^{22}$

Figure 1 shows the low temperature $(10 \mathrm{~K})$ PL spectra of AlN epilayers grown on sapphire $\left(\mathrm{AlN} / \mathrm{Al}_{2} \mathrm{O}_{3}\right), \mathrm{SiC}$
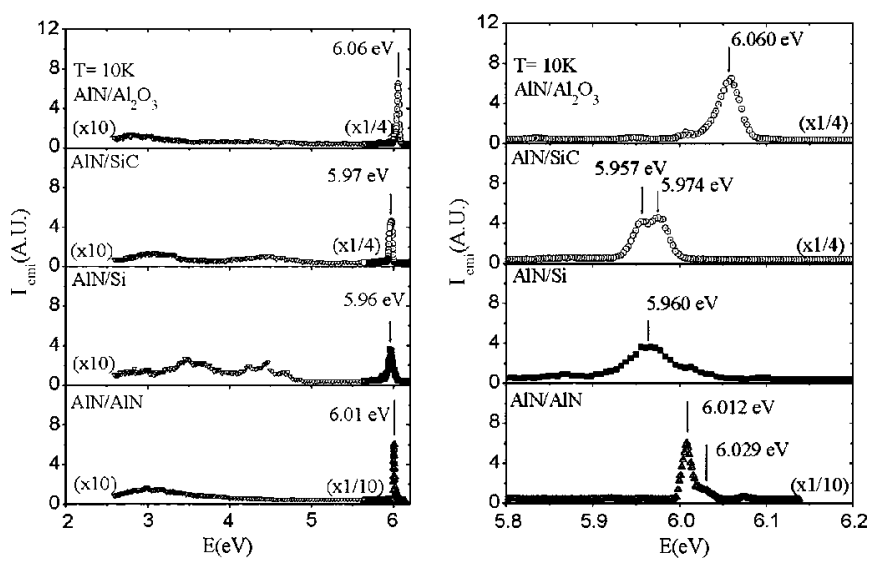

FIG. 1. $10 \mathrm{~K}$ PL spectra of $\mathrm{AlN} / \mathrm{Al}_{2} \mathrm{O}_{3}, \mathrm{AlN} / \mathrm{SiC}, \mathrm{AlN} / \mathrm{Si}$, and $\mathrm{AlN} / \mathrm{AlN}$ bulk, measured in (a) a broad spectral range from 2.4 to $6.2 \mathrm{eV}$ and (b) small spectral range from 5.8 to $6.2 \mathrm{eV}$. 

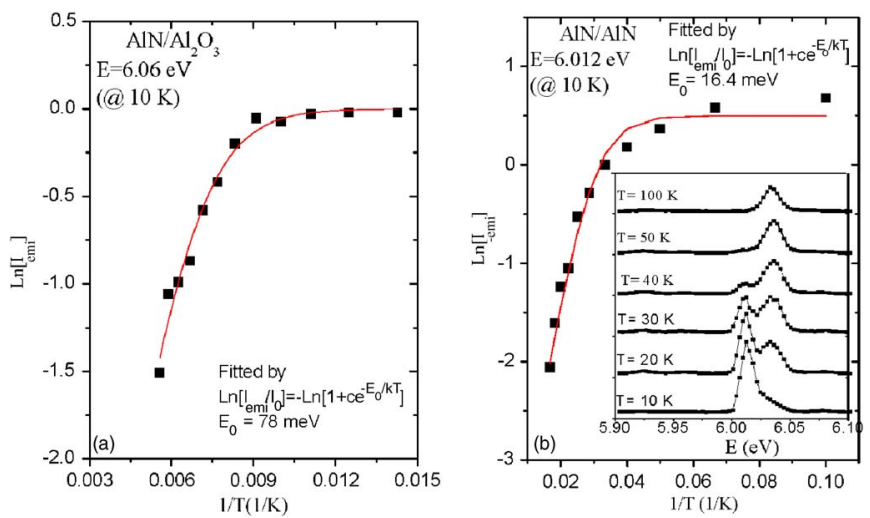

FIG. 2. (Color online) Arrhenius plot of the intensity of the dominant emission line $(6.060 \mathrm{eV}$ at $10 \mathrm{~K})$ in $\mathrm{AlN} / \mathrm{Al}_{2} \mathrm{O}_{3}$ epilayers. The measured activation energy is about $78 \mathrm{meV}$. (b) Arrhenius plot of the intensity of the lower energy emission line $(6.012 \mathrm{eV}$ at $10 \mathrm{~K})$ in AlN/AIN homoepilayers. The measured activation energy is about $16.4 \mathrm{meV}$. The inset shows the temperature evolution of the band edge emissions in AlN homoepilayers.

(AlN/SiC), Si (AlN/Si), and bulk AlN (AlN/AlN) substrates measured in (a) a broad spectral range from 2.4 to $6.2 \mathrm{eV}$ and (b) in a small spectral range from 5.8 to $6.2 \mathrm{eV}$. For all samples, the emission intensity of defect/impurity related lines is negligibly small compared to that of the band edge, which indicates that these AIN epilayers are of high purity. The integrated band edge emission intensity ratio is roughly 5:4:3:1 for $\mathrm{AlN} / \mathrm{AlN}, \mathrm{AlN} / \mathrm{Al}_{2} \mathrm{O}_{3}$, $\mathrm{AlN} / \mathrm{SiC}$, and $\mathrm{AlN} / \mathrm{Si}$ and the linewidth of the band edge emission line is narrowest for the AlN homoepilayer, implying that the homoepilayer possesses the highest crystalline quality as we expected.

The temperature evolutions of the emission spectra and intensity have been measured for all samples. $\mathrm{AlN} / \mathrm{Al}_{2} \mathrm{O}_{3}$ epilayers exhibit only one dominant emission peak with a position located at around $6.06 \mathrm{eV}$ at $10 \mathrm{~K}$. As illustrated in Fig. 2(a), the temperature dependence of the emission intensity of this line revealed an activation energy of about $78 \mathrm{meV}$, which is the measure of the binding energy of the FX in AlN epilayers ${ }^{14,15}$ and therefore we assign the $6.06 \mathrm{eV}$ emission line in $\mathrm{AlN} / \mathrm{Al}_{2} \mathrm{O}_{3}$ to the $\mathrm{FX}$ transition. On other hand, AlN/AlN and AlN/SiC epilayers exhibit two emission lines, where the higher energy emission line is due to the FX recombination and the lower energy emission peak is due to the donor-bound-exciton recombination $\left(I_{2}\right)$, based on the known value of about $16 \mathrm{meV}$ for the binding energy of the donor-bound excitons in AIN epilayers. ${ }^{23}$ Additionally, the temperature evolutions of the emission spectra and intensity, one of which is illustrated in Fig. 2(b), reveal an activation energy of about $16.4 \mathrm{meV}$ for the lower energy peak, which agrees very well with the spectral peak separation between the higher and lower energy peaks $(6.029-6.012 \mathrm{eV}$ $=17 \mathrm{meV}$ ) and further corroborates our assignment of $I_{2}$ and FX transitions. The inset of Fig. 2(b) also clearly shows that the $I_{2}$ emission intensity decreases with temperature more rapidly than that of the FX transition, which is expected because the donor bound excitons dissociate into FXs and neutral donors.

Compared to the FX transition in AlN/AlN, the observed energy position of the FX transition is $31 \mathrm{meV}$ higher in $\mathrm{AlN} / \mathrm{Al}_{2} \mathrm{O}_{3}$ due to a compressive strain and is 55 $(69 \mathrm{meV})$ lower in $\mathrm{AlN} / \mathrm{SiC}$ ( $\mathrm{AlN} / \mathrm{Si})$ due to a tensile strain. Although the integrated emission intensity is highest in AlN

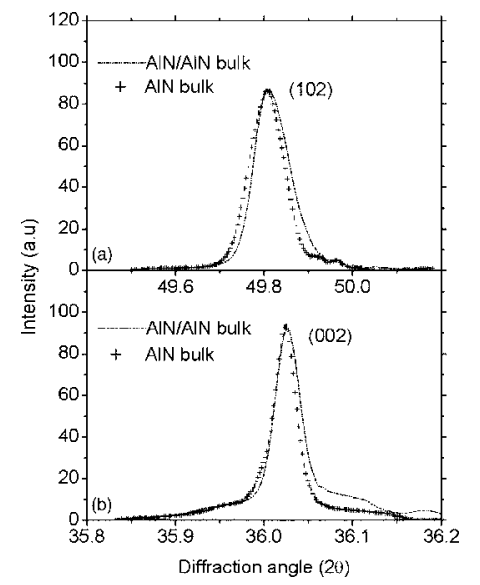

FIG. 3. Theta-2theta scan of (a) asymmetric (102) and (b) symmetric (002) reflection planes for an AlN homoepilayer and AlN bulk substrate.

homoepilayers, the dominant transition at low temperatures is $I_{2}$ rather than $\mathrm{FX}$, which indicates the presence of a higher unintentional donor impurity concentration in AIN/AIN than in $\mathrm{AlN} / \mathrm{Al}_{2} \mathrm{O}_{3}$. The presence of these impurities may be due to the diffusion of oxygen $(\mathrm{Si})$ atoms from the AlN ( $\mathrm{SiC})$ bulk substrate to the subsequent AlN epilayer during the epitaxial growth.

The lattice constants were determined using XRD by measuring the lattice parameters and the diffraction angles $(\theta)$ in $\theta / 2 \theta$ scans of (002), (102), and (105) reflection planes. An example of such measurements is shown in Fig. 3, where $\theta / 2 \theta$ scans of the symmetric (002) and asymmetric (102) planes of an AlN homoepilayer and AlN bulk substrate crystal are displayed. The results shown in Fig. 3 clearly indicate that the AlN homoepilayer is perfectly lattice matched to the AlN bulk substrate and almost strain-free. AlN homoepilayers have an in-plane lattice constant of $a=3.112 \AA$. The lattice constant $a$ increases in $\mathrm{AlN} / \mathrm{SiC}$ and $\mathrm{AlN} / \mathrm{Si}$ epilayers due to the presence of a tensile stress, while it decreases in $\mathrm{AlN} / \mathrm{Al}_{2} \mathrm{O}_{3}$ epilayers due to the presence of a compressive stress, consistent with the FX transition peak position shift observed in Fig. 1.

To see a more clear correlation between the FX transition peak position and the magnitude of strain in various AlN epilayers, we plot in Fig. 4(a) the variation of the FX transi-

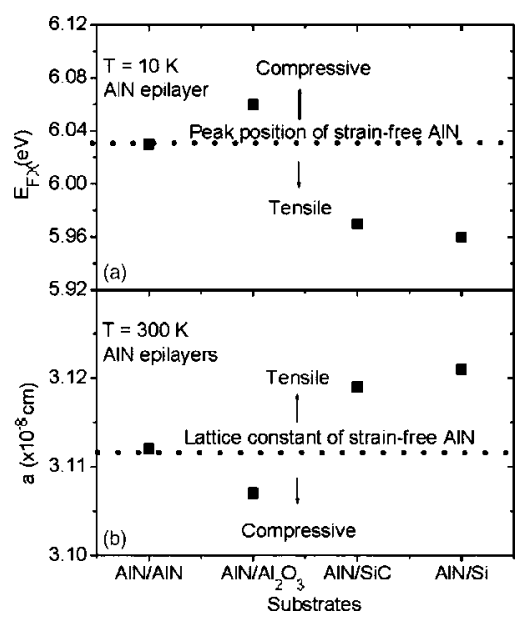

FIG. 4. Free exciton spectral peak positions $\left(E_{P}\right)$ and $(b)$ in-plane lattice constants $(a)$ of AlN epilayers grown on different substrates. Stress in $\mathrm{AlN} / \mathrm{Al}_{2} \mathrm{O}_{3}$ is compressive and is tensile in $\mathrm{AlN} / \mathrm{SiC}$ and $\mathrm{AlN} / \mathrm{Si}$ epilayers. 


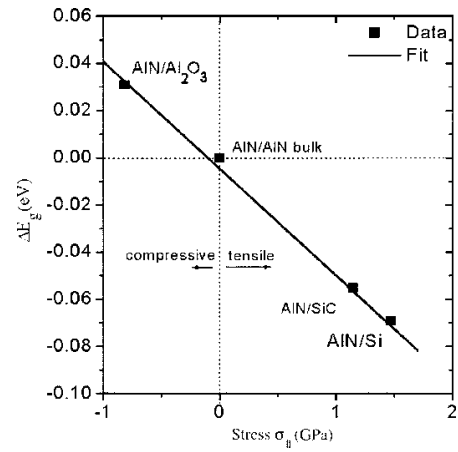

FIG. 5. Stress-induced shift of the free exciton emission peak position in AlN epilayers as a function of the in-plane stress. The solid line is the least-squares linear fit of the experimental data. The linear coefficient of stress-induced bandgap shift in AlN epilayers is deduced to be $45 \mathrm{meV} / \mathrm{GPa}$.

tion peak position and in Fig. 4(b) the variation of the inplane lattice constant $(a)$ of AlN epilayer with respect to the growth substrate. Based on the results shown in Fig. 3, an AlN epilayer is perfectly lattice matched to the AlN substrate and the FX emission peak position in AlN homoepilayers presents the position of unstrained AlN epilayers. A one-toone correlation between lattice constant and FX transition peak position shift with respect to that of the AlN homoepilayer can be clearly identified.

Based on the results shown in Fig. 4, the linear coefficient of stress-induced bandgap shift in AlN epilayer can be deduced, which is a fundamentally important parameter for the structural design of various devices. The in-plane stress $\sigma_{\|}$can be estimated from the relation: ${ }^{24}$

$$
\sigma_{\|}=\frac{a-a_{0}}{a_{0}}\left(C_{11}+C_{12}-2 \frac{C_{13}^{2}}{C_{33}}\right) \text {, }
$$

where $C_{i j}$ are the elastic constants of AlN $\left[C_{11}=410 \mathrm{GPa}\right.$, $C_{12}=140 \mathrm{GPa}, C_{13}=100 \mathrm{GPa}, C_{33}=390 \mathrm{GPa}$ (Ref. 25)], and $a_{0}$ is the in-plane lattice constant of strain-free bulk AlN (3.112 A). The FX emission peak position shift as a function of the in-plane stress is shown in Fig. 5 and a linear relationship is evident. The fact that all four data points perfectly fall on the straight line further validates our assignment of FX transitions in AlN epilayers grown on different substrates.

The experimental value of the linear coefficient for stress-induced FX transition (or bandgap) shift in AlN epilayers is $45 \mathrm{meV} / \mathrm{GaP}$, which is about $88 \%$ higher than that in $\mathrm{GaN}(24 \mathrm{meV} / \mathrm{GPa}){ }^{26}$ This higher value of linear coefficient of stress-induced bandgap shift in AlN than GaN is expected due to smaller lattice constant as well as higher mechanical strength of AlN than GaN. Although the value is deduced from the low temperature FX peak shift, the effect of measurement temperature is expected to be negligibly small. The results shown in Fig. 5 establish PL as a simple and effective method for monitoring the biaxial stress in AlN epilayers grown on different substrates and with different thicknesses, thereby providing a useful means for controlling and manipulating stress in AlN epilayers grown under different conditions.

In summary, DUV PL spectroscopy and XRD have been employed to study AlN epilayers grown on sapphire, $\mathrm{SiC}, \mathrm{Si}$, and AlN bulk substrates. The spectral peak positions of the FX transitions and the lattice constants were systematically measured for epilayers grown on different substrates. AlN homoepilayers were confirmed to have the same lattice parameters as AlN bulk crystals and to be strain-free. Furthermore, compressive stress in AlN/sapphire and tensile strain in $\mathrm{AlN} / \mathrm{SiC}$ and $\mathrm{AlN} / \mathrm{Si}$ were verified. The stress-induced shift of the free exciton transitions in AIN epilayers grown on different substrates has been measured and correlated with XRD results, from which the stress-induced bandgap shift of $45 \mathrm{meV} / \mathrm{GPa}$ in AlN epilayers was deduced, which is about $88 \%$ larger than that in GaN. The work here establishes PL as another simple and effective method for monitoring the substrate induced biaxial stress in AlN epilayers in addition to XRD measurements.

This research was supported by DOE (Grant No. DEFG03-96ER45604).

${ }^{1}$ Y. Taniyasu, M. Kasu, and T. Makimoto, Nature (London) 441, 325 (2006).

${ }^{2}$ J. Li, Z. Y. Fan, R. Dahal, M. L. Nakarmi, J. Y. Lin, and H. X. Jiang, Appl. Phys. Lett. 89, 213510 (2006).

${ }^{3}$ T. Matsutani, M. Kiuchi, K. Shirouzu, A. Yoshioka, R. Shimizu, and S. Takahashi, Solid State Phenom. 107, 43 (2005).

${ }^{4}$ V. Mortet, O. Elmazria, M. Nesladek, M. B. Assouar, G. Vanhoyland, J. D'Haen, M. D'Olieslaeger, and P. Alnot, Appl. Phys. Lett. 81, 1720 (2002).

${ }^{5}$ A. T. Sowers, J. A. Christman, M. D. Bremser, B. L. Ward, R. F. Davis, and R. J. Nemanich, Appl. Phys. Lett. 71, 2289 (1997).

${ }^{6}$ S. R. Lee, A. M. West, A. A. Allerman, K. E. Waldrip, D. M. Follstaedt, P. P. Provencio, D. D. Koleske, and C. R. Abernathy, Appl. Phys. Lett. 86, 241904 (2005).

${ }^{7}$ Q. S. Paduano, A. J. Drehman, D. W. Weyburne, J. Kozlowski, J. Seraflnczuk, J. Jasinski, and Z. Liliental-Weber, Phys. Status Solidi C 0, 2014 (2003).

${ }^{8}$ J. Bai, M. Dudley, W. H. Sun, H. M. Wang, and A. Khan, Appl. Phys. Lett. 88, 051903 (2006).

${ }^{9}$ R. Schlesser, R. Dalmau, R. Yakimova, and Z. Sitar, Mater. Res. Soc. Symp. Proc. 693, I9.4.1 (2002).

${ }^{10}$ L. J. Schowalter, G. A. Slack, J. B. Whitlock, K. Morgan, S. B. Schujman, B. Raghothamachar, M. Dudley, and K. R. Evans, Phys. Status Solidi C 0, 1997 (2003).

${ }^{11}$ Z. Gu, L. Du, J. H. Edgar, N. Nepal, H. X. Jiang, J. Y. Lin, and R. Witt, J. Cryst. Growth 297, 105 (2006).

${ }^{12}$ A. Watanabe, T. Takeuchi, K. Hirosawa, H. Amano, K. Hiramatsu, and I. Akasaki, J. Cryst. Growth 128, 391 (1993).

${ }^{13}$ N. Teofilov, K. Thonke, R. Sauer, D. G. Ebling, L. Kirste, and K. W. Benz, Diamond Relat. Mater. 10, 1300 (2001).

${ }^{14}$ J. Li, K. B. Nam, M. L. Nakarmi, J. Y. Lin, and H. X. Jiang, Appl. Phys. Lett. 83, 5163 (2003).

${ }^{15}$ K. B. Nam, J. Li, M. L. Nakarmi, J. Y. Lin, and H. X. Jiang, Appl. Phys. Lett. 84, 5264 (2004).

${ }^{16}$ C. M. Zetterling, M. Ostling, K. Wongchotigul, M. G. Spencer, X. Tang, C. I. Harris, N. Nordell, and S. S. Wong, J. Appl. Phys. 82, 2990 (1997).

${ }^{17}$ E. Silveria, J. A. Freitas, M. Kneissl, D. W. Treat, N. M. Jonson, G. A. Slack, and L. J. Schowalter, Appl. Phys. Lett. 84, 3501 (2004).

${ }^{18}$ E. Silveira, J. A. Freitas, O. J. Glembocki, G. A. Slack, and L. J. Schowalter, Phys. Rev. B 71, 041201 (2005).

${ }^{19}$ T. Shibita, K. Asai, S. Sumiya, M. Mouri, M. Tanaka, O. Oda, H. Katsukawa, H. Miyake, and K. Hiramatsu, Phys. Status Solidi C 0, 2023 (2003).

${ }^{20}$ J. Li, J. Y. Lin, and H. X. Jiang, Appl. Phys. Lett. 88, 171909 (2006).

${ }^{21}$ G. I. M. Prinz, A. Landenburger, M. Schirra, M. Feneberg, K. Thonke, R. Sauer, Y. Taniyasu, M. Kasu, and T. Makimoto, J. Appl. Phys. 101, 023511 (2007).

${ }^{22}$ http://www.phys.ksu.edu/area/GaNgroup

${ }^{23}$ K. B. Nam, J. Li, M. L. Nakarmi, J. Y. Lin, and H. X. Jiang, Appl. Phys. Lett. 82, 1694 (2003).

${ }^{24}$ V. S. Harutyunyan, A. P. Aivazyan, E. R. Weber, Y. Kim, Y. Park, and S. G. Subramanya, J. Phys. D 34, A35 (2001).

${ }^{25}$ C. Deger, E. Born, H. Angerer, O. Ambacher, M. Stutzmann, J. Hornsteiner, E. Riha, and G. Fischerauer, Appl. Phys. Lett. 72, 2400 (1998).

${ }^{26}$ W. Rieger, T. Metzger, H. Angerer, R. Dimitrov, O. Ambacher, and M. Stutzmann, Appl. Phys. Lett. 68, 970 (1996). 